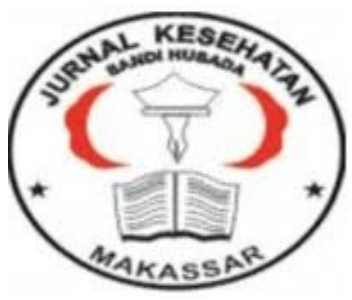

Jurnal Ilmiah Kesehatan Sandi Husada

hhttps://akper-sandikarsa.e-journal.id/JIKSH

Vol 11, No, 1, Juni 2020, pp;145-151

p-ISSN: 2354-6093 dan e-ISSN: 2654-4563

DOI: $10.35816 /$ jiskh.v10i2.233

\title{
Angka Kejadian Ileus Obstruktif Pada Pemeriksaan BNO 3 Posisi Di RSUD Abdul Moeloek
}

Obstructive Ileus Incidence Rate in Examination of BNO 3 Position in Abdul Moeloek Hospital

\section{Alfi Wahyudi' ${ }^{1}$, Andi Siswandi ${ }^{2}$, Ratna Purwaningrum³ ${ }^{3}$, Bella Cynthia Dewi ${ }^{4}$}

\author{
${ }^{1}$ Departemen Radiologi Fakultas Kedokteran, Universitas Malahayati \\ ${ }^{2}$ Departemen Of Surgery Fakultas Kedokteran, Universitas Malahayati \\ ${ }^{3}$ Departemen Biokimia Fakultas Kedokteran, Universitas Malahayati
}

${ }^{4}$ Program Pendidikan Dokter, Fakultas Kedokteran, Universitas Malahayati

\section{Artikel info \\ Artikel history: \\ Received; 16 Maret 2020 \\ Revised; 18 Maret 2020 \\ Accepted;21 Maret 2020}

\begin{abstract}
Abstrak
Latar Belakang : Ileus obstruktif (ileus mekanik) adalah suatu keadaan dimana isi lumen saluran cerna tidak dapat disalurkan ke distal karena adanya sumbatan atau hambatan mekanik. Penyebab ileus obstruksi berkaitan pada kelompok usia yang terserang dan letak obstruksi. Tujuan: Untuk mengetahui angka kejadian ileus obstruktif pada pemeriksaan BNO 3 posisi Metode : Penelitian ini merupakan penelitian deskriptif dengan pendekatan crosssectional. Sampel pada penelitian ini adalah seluruh catatan rekam medik pasien ileus obstruksi yang terdiagnosis melalui pemeriksaan BNO 3 posisi. Teknik pengambilan sampel pada penelitian ini menggunakan teknik total sampling sebanyak 30 responden. Analisis data menggunakan analisis univariat. Hasil : Diketahui distribusi frekuensi usia pasien ileus obstruktif melalui pemeriksaan BNO 3 posisi paling banyak rentan usia > 65 tahun sebanyak 30,0\% dengan jenis kelamin paling banyak pada responden berjenis kelamin laki-laki sebanyak 63,7\% serta letak ileus obstruktif paling banyak pada ileus obtruksi letak tinggi sebanyak 73,3\%. Kesimpulan : angka kejadian ileus obstrusi pada pemeriksaan BNO paling banyak pada usia > 65 tahun dengan jenis kelamin laki-laki serta letak ileus obstruksi letak tinggi.
\end{abstract}

\begin{abstract}
Background: Obstructive Ileus is a state where the contents of the lumen of the gastrointestinal tract cannot be transmitted to the distal due to mechanical obstruction or barriers. Causes of obstruction of ileus are related to the affected age group and obstruction location. Objective: To know the incidence of obstructive ileus on the examination of $B N O 3$ position in the radiology. Method: The research is a descriptive study with a cross-sectional approach. The samples in this study are all records of the medical record of obstruction ileus patients that were diagnosed through
\end{abstract}


examination of the BNO 3 position. The sampling technique used a total sampling technique of 30 respondents. Data analysis using univariate analysis. Results: unknown age frequency distribution of ileus obstructive patients diagnosed through the examination of BNO 3 most vulnerable positions aged $>65$ years as much as $30.0 \%$. The most genders in male female respondents as much as $63.7 \%$ and the location of most obstructive ileus in 73.3\%. Conclusion: The incidence of ileus obstrusion on most BNO examination at the age of $>65$ years with male gender and the location of high-level obstruction ileus

Keywords:

Ileus Obstruks; BNO 3 Posisi;
Coresponden author:

Email: bellacynthiadewi97@gmail.com

artikel dengan akses terbuka dibawah lisensi CC BY -4.0

\section{Pendahuluan}

Pengaruh globalisasi di segala bidang, perkembangan teknologi, dan industri telah banyak membawa perubahan pada perilaku dan gaya hidup masyarakat serta situasi lingkungannya, misalnya perubahan pola konsumsi makan, berkurangnya aktivitas fisik, dan meningkatnya pencemaran atau polusi lingkungan. Perubahan tersebut telah memberi pengaruh pada transisi epidemiologi yaitu beban ganda penyakit dengan meningkatnya beberapa penyakit menular dan penyakit tidak menular atau degeneratif. Salah satu jenis penyakit tidak menular adalah penyakit pada saluran pencernaan (Kemenkes RI, 2019). Ileus obstruktif merupakan suatu keadaan yang menyebabkan isi usus tidak bisa melewati lumen usus sebagai akibat adanya sumbatan atau hambatan mekanik . Hal ini dapat terjadi dikarenakan kelainan di dalam lumen usus, dinding usus, atau benda asing di luar usus yang menekan, serta kelainan vaskularisasi pada suatu segmen usus yang dapat menyebabkan nekrosis segmen usus. Ileus obstruktif merupakan suatu keadaan yang darurat sehingga memerlukan penanganan segera (Obaid, 2011).

Penyebab terjadinya ileus obstruksi pada usus halus antara lain hernia inkarserata, adhesi atau perlekatan usus, invaginasi (intususepsi), askariasis, volvulus ,tumor, batu empedu yang masuk ke ileus. Obstruksi pada neonatal terjadi pada 1/1.500 kelahiran hidup. Hasil penelitian Evans di Amerika Serikat menunjukkan hasil ada sekitar 3.000 bayi/tahun yang dilahirkan dengan obstruksi. Di Indonesia jumlahnya tidak jauh berbeda. Berdasarkan laporan rumah sakit di kabupaten Cirebon pada tahun 2006, Ileus obstruktif menduduki peringkat ke- 6 dari sepuluh penyakit penyebab kematian tertinggi pada kelompok umur 1-4 tahun dengan proporsi 3,34\% (Kemenkes RI, 2019). Pemeriksaan radiografi abdomen tiga posisi dilakukan dengan posisi (anteroposterior) AP supine, semi erect dan left lateral decubitus (LLD). Foto abdomen AP supine dilakukan dengan posisi pasien tidur telentang diatas meja pemeriksaan, kedua tangan disamping tubuh, sedangkan foto abdomen semi erect dilakukan dengan posisi pasien semi erect (duduk atau setengah duduk), kedua tangan disamping tubuh. Foto abdomen LLD dilakukan dengan posisi pasien true lateral, 
sisi kiri menempel film dan sisi kanan diatas dengan kedua tangan diatas kepala dan kedua lutut difleksikan.

Interpretasi radiografi abdomen tiga posisi pada pasien ini adalah properitoneal fat line masih tegas dan simetris, tampak distensi sebagian sistema usus halus dan colon, tampak gambaran air fluid level multiple panjang pendek dan tak tampak udara usus di regio rektum, mengarah ke suatu gambaran ileus obstruksi letak rendah tak tampak pneumoperitoneum, tak tampak gambaran udara subdiafragma maupun pada tempat tertinggi pada posisi LLD Sistema tulang tervisualisasi baik (Rillianti \& Oktarlina, 2017)

\section{Metode}

Penelitian deskriptif dengan pendekatan crosssectional yang bertujuan untuk mengetahui angka kejadian ileus obstruktif pada pemeriksaan BNO 3 posisi di Instalasi Radiologi RSUD Dr. H. Abdul Moeloek Bandar Lampung tahun 2017-2018. Populasi pada penelitian ini adalah seluruh catatan rekam medik pasien ileus obstruksi dengan pemeriksaan BNO 3 posisi yang berobat di rumah sakit Abdul Moeloek periode tahun 2017-2018.

Pengumpulan data skunder dengan menggunakan teknik total sampling sebanyak 30 responden. Kriteris Inklusi pada penelitian ini adalah pasien yang didiagnosis ileus obstruktif melalui pemeriksaan BNO 3 posisi pada tahun 2017-2018, pasien ileus obstruktif yang didiagnosis melalui pemeriksaan BNO 3 posisi yang memiliki data rekam medik di RSUD Dr. H. Abdul Moeloek Bandar Lampung. Kriteria Ekslusi pada penelitian ini adalah pasien yang terdiagnosis ileus obstruktif namun bukan melalui pemeriksaan BNO 3 posisi, pasien ileus obstruktif yang memiliki data rekam medik yang tidak terbaca dan hilang di RSUD Dr. H. Abdul Moeloek Bandar Lampung. Variabel independent dalam penelitian ini adalah pemeriksaan BNO 3 posisi, variabel dependent dalam penelitian ini adalah angka kejadian ileus obstruktif. Pengolahan data menggunakan analisis univariat untuk mengatahui prevalensi variabel independen dan variabel dependen.

\section{Hasil Dan Pembahasan}

Tabel 1 Distribusi frekuensi usia pasien ileus obstruktif yang didiagnosis melalui pemeriksaan BNO 3 posisi di Instalasi Radiologi RSUD Dr. H. Abdul Moeloek Bandar Lampung tahun 2017-2018

\begin{tabular}{clcc}
\hline No & Umur & $\mathbf{N}$ & $\mathbf{\%}$ \\
\hline 1 & $0-5$ tahun & - & - \\
2 & $6-11$ tahun & - & - \\
3 & $12-16$ tahun & - & - \\
4 & $17-25$ tahun & 2 & 6,7 \\
5 & $26-35$ tahun & 3 & 10,0 \\
6 & $36-45$ tahun & 4 & 13,3 \\
7 & $46-55$ tahun & 8 & 26,7 \\
8 & $56-65$ tahun & 4 & 13,3 \\
9 & $>65$ tahun & 9 & 30,0 \\
& Jumlah & $\mathbf{3 0}$ & $\mathbf{1 0 0}$ \\
\hline
\end{tabular}


Tabel 2. Distribusi frekuensi jenis kelamin pasien ileus obstruktif yang didiagnosis melalui pemeriksaan BNO 3 posisi di Instalasi Radiologi RSUD Dr. H. Abdul Moeloek Bandar Lampung tahun 2017-2018

\begin{tabular}{clcc}
\hline No & Jenis Kelamin & $\mathbf{N}$ & $\mathbf{\%}$ \\
\hline 1 & Laki-laki & 19 & 63,3 \\
2 & Perempuan & 11 & 36,7 \\
& Jumlah & $\mathbf{3 0}$ & $\mathbf{1 0 0}$ \\
\hline
\end{tabular}

Tabel 3 : Distribusi frekuensi letak ileus obstruktif yang didiagnosis melalui pemeriksaan BNO 3 posisi di Instalasi Radiologi RSUD Dr. H. Abdul Moeloek Bandar Lampung tahun 2017-2018

\begin{tabular}{clcc}
\hline No & Letak iileus obstruktif & $\mathbf{N}$ & \% \\
\hline 1 & Ileus obstruktif letak tinggi & 22 & 73,3 \\
2 & Ileus obstruktif letak rendah & 8 & 26,7 \\
& Jumlah & $\mathbf{3 0}$ & $\mathbf{1 0 0}$ \\
\hline
\end{tabular}

Usia

Distribusi frekuensi pasien ileus obstruktif berdasarkan usia diketahui hasil penelitian dari data rekam medik pasien dari 30 responden paling banyak pada rentan usia $>65$ tahun sebanyak $9(30,0 \%)$ responden dan paling sedikit pada rata-rata usia 17 - 25 tahun sebanyak $2(6,7 \%)$ responden. Menurut kepustakaan insidensi tertinggi ileus obstruktif pada anak adalah usia dibawah 1 tahun dan usia lanjut ( $>65$ tahun). Usia yang menyebabkan obstruksi usus tergantung dari onset munculnya gejala dan penyebab obstruksinya, pasien dengan atresia usus (Sari et al., 2015). Penelitian serupa yang telah dilakukan oleh Deshmukh dkk di rumah sakit Solapur pada tahun 2012-2014 yang menunjukkan usia lanjut dimana pada penelitian ini usia dikelompokan kedalam 7 kelompok didapatkan bahwa ileus obstruksi banyak diderita oleh usia 50-60 tahun sebanyak 22\%, 61-70 tahun 18\% dan paling sedikit rata-rata usia < 18 tahun sebanyak $8 \%$ hal ini disebabkan karena bertambahnya usia daya tahan tubu serta fungsi organ menururun (Ismail et al., 2005). Namun hasil berbeda dengan hasil penelitian Serin A dkk pada tahun 2017 tentang karakteristik penderita ileus obstruksi, pada penelitian ini menunjukkan bahwa pasien ileus obstruksi meningkat pada usia 6-11 tahun, kejadian menurun pada usia 12-45 tahun dan meningkat kembali pada usia $>45$ tahun. Pada penelitian yang dilakukan pada 40 responden paling banyak didapatkan pada usia 6-11 tahun sebanyak 8 responden, pada penelitian ini peneliti mengemukakan bahwa kejadian ileus obstruksi tidak dipengaruhi oleh usia, namun demikian kejadian ileus obstruksi lebih sering menyerang anak - anak hal ini dikarenakan penyumbatan pada saluran pencernaan pada anak disebabkan intususepsi (Manurung et al., 2016).

\section{Jenis kelamin}


Distribusi frekuensi pasien ileus obstruktif berdasarkan jenis kelamin diketahui berdasarkan hasil penelitian dari data rekam medik pasien dari 30 responden paling banyak pada responden dengan jenis kelamin laki-laki sebanyak 19 $(63,7 \%)$ responden. Menurut kepustakaan laki - laki lebih berisiko dari pada perempuan, namun hal tersebut belum bisa dijelaskan (Jain et al., 2010). Hasil sejalan dengan penelitian Ullah pada 576 pasien dimana penderita ileus obstruksi cenderung lebih banyak terjadi pada laki-laki dibanding perempuan, didapatkan $60 \%$ berjenis kelamin laki-laki, namun belum bisa membuktikan bahwa laki-laki lebih beresiko menderita ileus obstruksi daripada wanita (Qureshi et al., 2017). Hasil pun sejalan dengan hasil penelitian Serin A dkk pada tahun 2017 tentang karakteristik penderita ileus obstruksi, pada penelitian ini menunjukkan bahwa jumlah frekuensi penderita ileus obstruksi berdasarkan karakteristik jenis kelamin, paling banyak papa pasien dengan jenis kelamin laki-laki sebanyak 65\% (Manurung et al., 2016).

\section{Letak ileus obstruktif}

Ileus obstruktif adalah suatu keadaan dimana isi lumen saluran cerna tidak dapat disalurkan ke distal karena adanya sumbatan atau hambatan mekanik yang disebabkan kelainan dalam lumen usus, dinding usus atau luar usus yang menekan atau kelainan vaskularisasi pada suatu segmen usus yang menyebabkan nekrose segmen usus tersebut. Pemeriksaan radiografi abdomen tiga posisi dilakukan dengan posisi (anteroposterior) AP supine, semi erect dan left lateral decubitus (LLD). Foto abdomen AP supine dilakukan dengan posisi pasien tidur telentang diatas meja pemeriksaan, kedua tangan disamping tubuh, sedangkan foto abdomen semi erect dilakukan dengan posisi pasien semi erect (duduk atau setengah duduk), kedua tangan disamping tubuh. Foto abdomen LLD dilakukan dengan posisi pasien true lateral, sisi kiri menempel film dan sisi kanan diatas dengan kedua tangan diatas kepala dan kedua lutut difleksikan.

Interpretasi radiografi abdomen tiga posisi pada pasien ini adalah properitoneal fat line masih tegas dan simetris, tampak distensi sebagian sistema usus halus dan colon, tampak gambaran air fluid level multiple panjang pendek dan tak tampak udara usus di regio rektum, mengarah ke suatu gambaran ileus obstruksi letak rendah tak tampak pneumoperitoneum, tak tampak gambaran udara subdiafragma maupun pada tempat tertinggi pada posisi LLD Sistema tulang tervisualisasi baik (Rillianti \& Oktarlina, 2017). Hasil penelitian menunjukkan bahwa hasil pemeriksaan BNO 3 posisi pada pasien ileus obstruksi paling banyak pada ileus obtruksi letak tinggi sebanyak 22 (73,3\%) responden. Letak tinggi terjadi pada usus halus, obstruksi yang terjadi pada letak tinggi adalah atresia/stenosis duodenum, jejenum, dan ileum, hipertrofi pylorus stenosis, intususepsi, hernia, adhesi, volvulus midgut. Obstruksi letak rendah adalah obstruksi yang terjadi di 
usus besar, seperti hirschsprung, atresia ani, intususepsi, volvulus sigmoid (Malik et al., 2010). Hasil penelitian tentang letak obstruksi yang sesuai dengan penelitian yang peneliti lakukan belum dapat ditemukan, namun penelitian tentang letak obstruksi yang dilakukan oleh Obaid Khadim pada usia 10 - 80 tahun, ditemukan obstruksi letak tinggi 68 (73,9\%) lebih banyak daripada letak rendah $24(26,1 \%)$, hal ini dikarenakan pada penelitian Obaid Khadim penyebab terbanyak obstruksi usus adalah hernia dan adhesi.

Hasil berbeda dengan hasil penelitian Sari N (2015) tentang gambaran ileus obstruktif di RSUD Arifin Achmad Provinsi Riau Periode Januari 2012 - Desember 2014 menunjukkan hasil paling banyak pada letak ileus rendah sebanyak 75,6\% hal ini disebabkan karena ileus Letak rendah merupakan letak obstruksi yang paling banyak terdapat pada penelitian ini, karena penyebab terbanyak ileus obstruktif adalah penyakit hirschsprung, adhesi, atresia ani, dan intususepsi. Letak obstruksi dilihat dari penyebab obstruksinya, pada penelitian ini hirchsprung merupakan penyebab yang paling sering terjadi, karena kegagalan migrasi sel ganglion sepanjang gastrointestinal sampai ke distal, penyakit hirschsprung sering terjadi di retosigmoid. Pada penelitian ini adhesi dikarenakan perleketan pasca operasi dari penyakit hirschsprung sehingga perleketan tersebut terjadi di kolon. Pada atresia ani disebabkan karena kelainan pembentukkan kloaka, kelainan tersebut karena kurangnya rekanalisasi dari bagian bawah lubang anus (Sari et al., 2015).

\section{Simpulan Dan Saran}

Berdasarkan hasil penelitian yang telah dilakukan dibagian rekam medik Rumah Sakit Dr.H.Abdul Moeloek tahun 2017-2018 dapat ditarik kesimpulan bahwa diketahui distribusi frekuensi usia pasien ileus obstruktif yang didiagnosis melalui pemeriksaan BNO 3 posisi paling banyak rentan usia $>65$ tahun sebanyak $9(30,0 \%)$ responden dengan kelamin laki-laki paling banyak sebanyak $19(63,7 \%)$ responden dan letak ileus obstruktif paling banyak pada ileus obtruksi letak tinggi sebanyak 22 (73,3\%) responden. Disarankan supaya perlu diadakan lagi penelitian lebih lanjut dengan faktor-faktor yang meningkatkan kejadian ileus obstruksi seperti gejala klinis, komplikasi

\section{Daftar Rujukan}

Indriyani M.N, 2013, 'Diagnosis Dan Tata Laksana Ileus Obstruktif', E-jurnal Medica UDAYANA, diakses dari : http: // ojs.unud.ac.id/ indeks. php/eum/article/view/5113/3903.

Ismail, Khan, M., Shah, S. A., \& Ali, N. (2005). Pattern of dynamic intestinal obstruction in adults. Journal of Postgraduate Medical Institute, 19(2), 157-161.

Jain, B. K., Arora, H., Kumar, U., Mohanty, D., \& Garg, P. K. (2010). Insight into the management of non-traumatic perforation of the small intestine. Journal of 
Infection in Developing Countries, 4(10), 650-654. https://doi.org/10.3855/jidc.829

Kemenkes RI. (2019). Profil Kesehatan Indonesia 2018 [Indonesia Health Profile 2018]. http://www.depkes.go.id/resources/download/pusdatin/profil-kesehatanindonesia/Data-dan-Informasi_Profil-Kesehatan-Indonesia-2018.pdf

Malik, A., Shah, M., Pathan, R., \& Sufi, K. (2010). Pattern of acute intestinal obstruction: Is There a change in the underlying etiology. Saudi Journal of Gastroenterology, 16(4), 272-274. https://doi.org/10.4103/1319-3767.70613

Manurung, F. R., Simangunsong, B., \& Siagian, P. (2016). Karakteristik Penderita Apendisitis Akut yang Dirawat Inap di RSUD Lubuk Pakam Deli Serdang Tahun 2015-2016. 2015-2018.

Obaid, K. J. (2011). Intestinal Obstruction : Etiology , Correlation between Pre- Operative and Operative Diagnosis. International Journal of Public Health Research Special Issue, 41-49.

Qureshi, N. A., Bhat, S. K., \& Sodhi, B. S. (2017). Spectrum of Etiology of Intestinal Obstruction - A Hospital-based Study. International Journal of Scientific Study, 5(5), 85-89. https://doi.org/10.17354/ijss/2017/399

Rillianti, D., \& Oktarlina, R. Z. (2017). Radiografi Abdomen 3 posisi pada Kasus Neonatus dengan Meteorismus. Jurnal Medula Unila, 7(April).

Sari, N., Ismar, \& Nazriati, E. (2015). Gambaran Ileus Obstruktif pada Anak di RSUD Arifon Achmad Provinsi Riau Periode Januari 2012-Desember 2014. Jom Fk, 2(2), 1-19. 